\title{
Síndrome miasténico de Eaton-Lambert
}

\author{
Juan Carlos Cataño
}

Facultad de Medicina, Universidad de Antioquia, Medellín, Antioquia

\begin{abstract}
Se presenta el caso de una mujer de 70 años sin antecedentes patológicos de importancia, que ingresó a un hospital local con fatiga, debilidad muscular de las extremidades y visión doble.

En el examen físico se observaba ptosis palpebral bilateral (figura 1), paresia facial, atrofia muscular proximal de las extremidades dominantes y arreflexia generalizada. Con el diagnóstico presuntivo de miastenia gravis, se practicó una electromiografía que mostró una amplitud anormalmente baja de los potenciales de acción muscular y un gran aumento después de repetidas estimulaciones a $50 \mathrm{~Hz}$, lo cual es muy sugestivo del síndrome miasténico de Eaton-Lambert.

Se hizo una tamización general en busca de neoplasias y se encontró en la radiografía de tórax una masa en el mediastino anterior (figura 2), razón por la cual se le practicó posteriormente timectomía total; la histopatología del timo concluyó que se trataba de un timoma de tipo B1 que mostraba aún áreas de corteza y médula de timo normales (figura 3). Luego de la timectomía, la paciente mejoró de la mayoría de sus síntomas miasténicos.

Si bien la mayoría de casos de síndrome miasténico de Eaton-Lambert se asocian a carcinoma pulmonar de células pequeñas, aquí se presenta un raro pero ilustrativo caso asociado a timoma.
\end{abstract}

Palabras clave: miastenia gravis, timoma, síndrome miasténico de Eaton-Lambert, neoplasias, timectomía

\section{Eaton-Lambert myasthenic syndrome}

A 70-year-old woman without unusual medical history was admitted at a local hospital with complaints of fatigue, muscle weakness in the extremities and double vision. On examination, bilateral ptosis (figure 1), facial paresis, proximal-dominant limb muscle atrophy and generalized arreflexia were observed. On the basis of tentative diagnosis of myasthenia gravis, an electrodiagnostic study was conducted. It demonstrated abnormally low-amplitude muscular action potentials, but with a large increase after repetitive stimulation at $50 \mathrm{~Hz}$. These responses are characteristic of the Eaton-Lambert myasthenic syndrome. A screening for malignant diseases was performed and chest radiography showed an anterior mediastinal mass (figure 2). The patient was scheduled for thymectomy, and subsequent histopathology of the thymus gland revealed a type B1 thymoma with areas reminiscent of a normal thymic cortex and medulla (figure 3). After the thymectomy most of the myasthenic symptoms were no longer in evidence. Generally, the Eaton-Lambert myasthenic syndrome is associated with small cell lung carcinoma, but this was an illustrative case associated with thymoma.

Key words: Myasthenia gravis, thymoma, Lambert-Eaton myasthenic syndrome, neoplasms, thymectomy.

\section{Consideraciones éticas}

Se realizó el proceso de consentimiento informado al paciente, quien firmó el documento correspondiente para la realización de esta publicación.

\section{Conflicto de interés}

El autor del manuscrito declara no tener ningún conflicto de interés.

\author{
Correspondencia: \\ Juan Carlos Cataño, Calle 8 sur № 43 B-112, Medellín, \\ Colombia \\ Teléfono: (574) (314) 6175507 \\ kataju@hotmail.com
}

Recibido: 18/12/09; aceptado:12/04/10

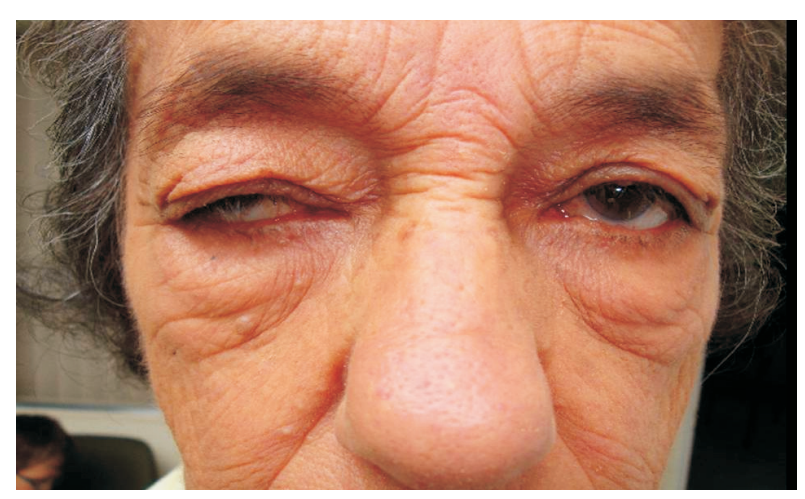

Figura 1. Ptosis palpebral y desviación ocular por paresia de los músculos oculares. 


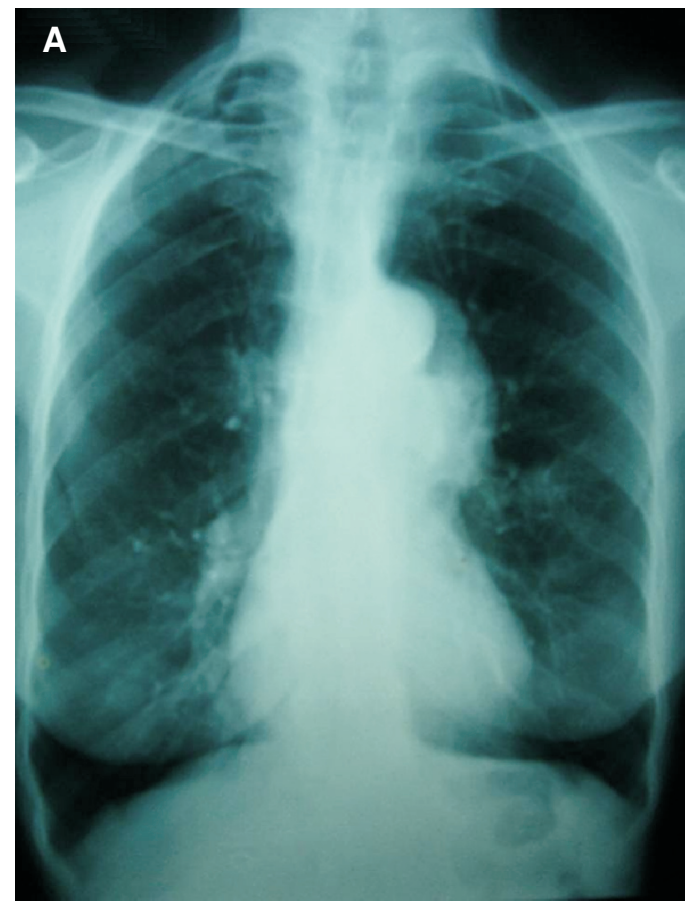

Figura 2A. Radiografía postero-anterior de tórax en la que se observa la masa del mediastino anterior que sobresale del cayado aórtico.

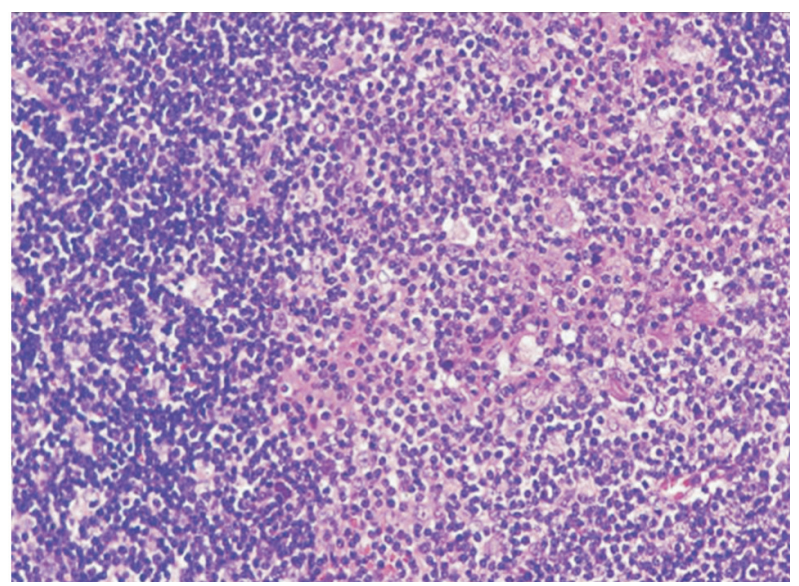

Figura 3. Histopatología de la masa del mediastino que muestra un timoma de tipo B1. Hematoxilina-eosina, 100X.

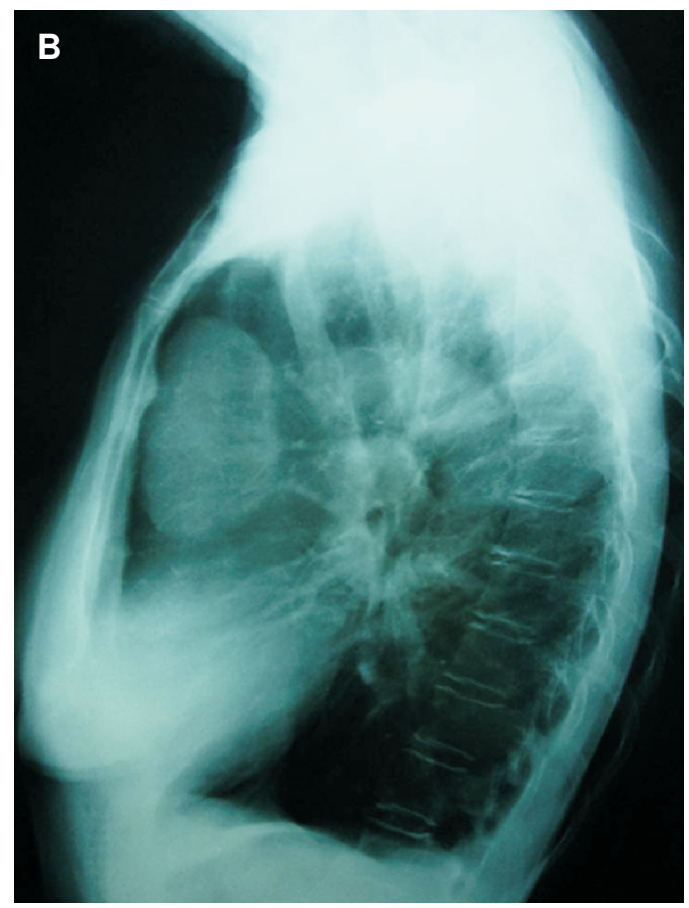

Figura 2B. Radiografía lateral de tórax en la que se observa la masa del mediastino anterior.

\section{Financiación}

El autor declara no haber recibido ningún tipo de financiación para la realización del presente manuscrito; los costos de las pruebas diagnósticas y de los estudios anatomopatológicos realizados a la paciente fueron cubiertos por su EPS como parte de la atención integral que recibió para su enfermedad. 